\title{
VIABILIDADE DE IMPLANTAÇÃO DE UMA AGROINDÚSTRIA DE BENEFICIAMENTO DE LEITE EM UM SÍTIO DE AGRICULTURA FAMILIAR
}

\author{
Leandro Carvalho BASSOTTO ${ }^{1}$ \\ Marina Ariente ANGELOCCI ${ }^{2}$ \\ ${ }^{1}$ Mestrando em Sistemas de Produção na Agropecuária, Universidade José do Rosário Vellano (Unifenas), \\ consultorialcb@yahoo.com.br. \\ 2. Docente no Programa de Mestrado Profissional em Sistemas de Produção na Agropecuária, Universidade José do Rosário \\ Vellano (Unifenas), msarient@hotmail.com.
}

Recebido em: 26/08/2016 - Aprovado em: 10/11/2017 - Disponibilizado em: 30/12/2017

\begin{abstract}
RESUMO
O Agronegócio é um dos grandes responsáveis pelo desenvolvimento e crescimento do Brasil. Um exemplo são os insumos agrícolas comercializados em moeda estrangeira que colaboram com o aumento dos custos produtivos. Surge, então, a necessidade de buscar formas alternativas que visem contornar algumas dificuldades dos produtores, de modo que seja possível aumentar a viabilidade do trabalho no campo, garantindo maior rentabilidade dos negócios agropecuários. Dessa forma, o objetivo deste artigo é analisar a viabilidade econômica do processo de beneficiamento da produção leiteira em uma empresa rural com mão de obra familiar da cidade de Campestre, MG. Como metodologia, o estudo teve como foco a análise de um sítio familiar no Sul de Minas Gerais. Para o estudo, foi utilizado um software gratuito do SEBRAE que auxilia empreendedores na alavancagem de seus respectivos negócios. Como resultado, verificou-se que, como a estrutura desenvolvida seria demasiada grande, o ideal seria a construção das dependências físicas de acordo com as normas da Secretaria de Vigilância Sanitária Municipal, fator que permitiria construir uma estrutura física que abrigasse apenas o suficiente para o beneficiamento e comercialização da produção de 200 a 400 litros/dia de leite.

Palavras-chave:Agronegócio. Custos. Leite. Produção. Viabilidade.
\end{abstract}

\section{FEASIBILITY OF IMPLEMENTATION OF A MILK PROCESSING OF AGRIBUSINESS IN A FARMING FAMILY SITE}

\begin{abstract}
Agribusiness is largely responsible for the development and growth of Brazil. One example is the agricultural inputs traded in foreign currency collaborating with rising production costs. Then comes the need to seek alternative ways designed to circumvent some difficulties of the producers, so that it is possible to increase the viability of the work in the field, ensuring greater profitability of agricultural business. Thus, the purpose of this article is to analyze the economic viability of milk production beneficiation process in a rural enterprise with family labor of the town of Campestre, MG. As methodology, the study focused on the analysis of a familiar site in the South of Minas Gerais. For the study, we used a SEBRAE free software that assists entrepreneurs in leveraging their business. As a result, it was found that as the developed structure would be too large, the ideal would be the construction of physical facilities in accordance with the rules of the Municipal Department of Health Surveillance, a factor that would build a physical structure that housed just enough to processing and marketing of production of 200 to 400 liters / day milk.
\end{abstract}

Keywords: Agribusiness. Costs. Milk. Production. Viability.

\section{INTRODUÇÃO}

O Agronegócio é um dos grandes

quarto de todo o Produto Interno Bruto (PIB) responsáveis pelo desenvolvimento e provém deste segmento, capaz de aquecer crescimento do Brasil. Aproximadamente um diversos setores e contribuir para o crescimento 
e promoção das inúmeras atividades econômicas nacionais (NOVAIS et. al., 2010).

Todavia, embora tenha grande importância para a Economia Brasileira, o agronegócio é rotineiramente penalizado pelas adversidades que podem ser constatadas por aqueles que trabalham no campo. Não bastando as intemperanças da natureza que sempre colocam em risco o bom desenvolvimento dos negócios agrícolas, outros tantos fatores acabam por influenciar direta e indiretamente o processo de produção e comercialização dos produtos (HUMPHREY, 2006).

Um exemplo sãoos insumos agrícolas comercializados em moeda estrangeira (dólar), colaborando com o aumento dos custos produtivos, uma vez que a venda dos mesmos não consegue acompanhar as altas dos preços dos insumos. Os produtores rurais também sofrem com os inúmeros atravessadores que compram suas mercadorias por preços aquém dos praticados pelo mercado, obtendo assim, grande margem de lucro sobre os produtos agrícolas.

Dessa forma, surgiu a necessidade de buscar formas alternativas que visem contornar algumas dificuldades, de modo que seja possível aumentar a viabilidade do trabalho no campo, garantindo aos produtores rurais, maior rentabilidade dos negócios agropecuários.

Assim, o objetivo deste artigo é analisar a viabilidade econômica do processo de beneficiamento da produção leiteira em uma empresa rural com mão de obra familiar da cidade de Campestre, MG.

\section{MATERIAL E MÉTODOS}

Desenvolver qualquer tipo de atividade remunerada, formalizada ou não, é compreendida como empresa. Toda empresa explora um negócio com o propósito de atingir determinado objetivo, como lucratividade ou atendimento de determinadas necessidades sociais (CHIAVENATO, 2008).

O estudo teve como foco a análise de um sítio familiar na região do Sul de Minas Gerais. O produtor começou a investir na pecuária leiteira em 2010, quando atingia cerca de 30 litros de leite por dia. Com poucos recursos disponíveis e uma estrutura bastante rudimentar para a produção láctea, os primeiros investimentos foram simples. Um ano depois, a produção ultrapassava 150 litros por dia.

Com o avanço da produção leiteira, a esposa do produtor começou a fabricar iogurte caseiro e servir para visitas que passaram a comprar o iogurte fabricado na propriedade, além de difundir a qualidade do produto na cidade de Campestre. Pouco tempo depois, a propriedade rural começou a produzir iogurte caseiro sob encomenda e comercializá-lo em Campestre. Com tantos pedidos surgiu a necessidade de utilização de maior quantidade de leite. 
Entretanto, verificou-se uma limitação para o beneficiamento de maior volume de leite, de modo que a comercialização do iogurte foi estagnada, uma vez que o negócio necessitava de investimentos.Assim surgiu a primeira ideia de beneficiamento da produção de leite onde o volume produzido poderia ser totalmente convertido em iogurte e negociado diretamente com o mercado varejista de Campestre.

A primeira etapa do estudo foi uma pesquisa de marketing responsável por mensurar a demanda do mercado. Essa pesquisa foi desenvolvida em Campestre, cidade onde o produtor pretendia inserir toda a produção beneficiada.

O desenvolvimento dessa pesquisa de marketing permitiu o conhecimento da demanda real por produtos lácteos bem como a aceitação de um produto novo. As informações obtidas seriam fundamentais para o desenvolvimento do plano de negócios com base nas reais necessidades do mercado.

O plano de negócios foi elaborado como ferramenta de gestão necessária para medir a viabilidade econômica do empreendimento. $\mathrm{O}$ plano é fundamental para avaliar eventuais níveis de rentabilidade, além de facilitar a percepção das principais dificuldades de um negócio nos primeiros anos de funcionamento (AUSTIN et. al., 2012).
Para o estudo, foi utilizado um software gratuito do SEBRAE que auxilia empreendedores na alavancagem de seus respectivos negócios e que, muitas vezes, não têm condições de assumir os custos do desenvolvimento dessa ferramenta administrativa por empresas especializadas. O software encontra-se disponível no site da instituição, com um manual que auxilia empreendedores iniciantes a elaborar um plano de negócios eficiente e que atenda às reais necessidades apresentadas.

Para que a análise econômica fosse desenvolvida, o primeiro passo utilizado foi a pesquisa nos órgãos físcalizadores competentes para identificar quais seriam as exigências necessárias para a autorização de funcionamento da agroindústria de beneficiamento de leite.

Por se tratar de produção familiar, não foi considerada inicialmente a possibilidade de construção de uma indústria de laticínios, mas uma pequena fábrica que pudesse produzir e comercializar toda a produção beneficiada em Campestre. A Secretaria de Vigilância Sanitária Municipal foi acionada e constatou-se que, devido a inexistência de leis orgânicas que regulamentassem a fiscalização pela instituição, a mesma era incapaz de prestar qualquer orientação. Neste caso, a responsabilidade foi transferida para o Instituto Mineiro de Agropecuária (IMA), órgão responsável pela fiscalização estadual. 
Porém, a legislação estadual que regulamenta a estrutura e funcionamento das agroindústrias exige a construção mínima necessária para esse tipo de negócio, sendo maior que a necessidade do produtor, que pretendia beneficiar entre 200 e 400 litros de leite/dia. A estrutura física recomendada pelo IMA permitiria a produção de 3.000 litros de leite/dia.

Abaixo, são apresentados os dados levantados e utilizados para a análise econômica do novo negócio.

Quadro 1 - Investimentos fixos necessários

\begin{tabular}{|l|c|l|l|}
\hline \multicolumn{1}{|c|}{ Descrição } & Qtde & $\begin{array}{c}\text { Valor } \\
\text { Unitário - } \\
\text { R\$ }\end{array}$ & \multicolumn{1}{|c|}{ Total - R\$ } \\
\hline $\begin{array}{l}\text { Instalação } \\
\text { segundo normas } \\
\text { do IMA }\end{array}$ & 1 & $100.800,00$ & $100.800,00$ \\
\hline $\begin{array}{l}\text { Fermentadora } \\
\text { para iogurte - } \\
\text { capacidade 500 } \\
\text { litros }\end{array}$ & 1 & $8.600,00$ & $8.600,00$ \\
\hline $\begin{array}{l}\text { Pasteurizador } \\
\text { automático }\end{array}$ & 1 & $18.000,00$ & $18.000,00$ \\
\hline $\begin{array}{l}\text { Bomba para } \\
\text { transposição de } \\
\text { leite }\end{array}$ & 1 & $1.150,00$ & $1.150,00$ \\
\hline Empacotadeira & 1 & $15.000,00$ & $15.000,00$ \\
\hline $\begin{array}{l}\text { Mesa de Inox } \\
1,8 / 0,9 \text { metros }\end{array}$ & 1 & $1.900,00$ & $1.900,00$ \\
\hline $\begin{array}{l}\text { Mesa para } \\
\text { computador }\end{array}$ & 1 & 200,00 & 200,00 \\
\hline $\begin{array}{l}\text { Fiat Strada } \\
2011\end{array}$ & 1 & $24.446,00$ & $24.446,00$ \\
\hline Computador & 1 & $1.500,00$ & $1.500,00$ \\
\hline Total & $171.596,00$ \\
\hline Fonte: Os auto & & & \\
\hline
\end{tabular}

Fonte: Os autores.

Os investimentos fixos apresentados (Quadro 1) demonstram todas as máquinas e equipamentos necessários para a gestão e produção e o valor estimado de uma estrutura física a ser construída que atenda aos padrões do IMA.

Considera-se também que a empresa precisará de um capital de giro para custear as despesas mensais que ocorrerão na atividade como insumos, custos fixos mensais, entre outros. O Quadro 2 apresenta o custo total necessário para que o negócio possa ser implantado. Foi verificada a necessidade líquida de capital de giro de 44 dias, sendo que para 30 dias o valor necessário de capital é de $\mathrm{R} \$$ $28.425,85$. Já para 44 dias, o valor é de $\mathrm{R} \$$ 41.691,25 (44 dias / 30 dias $=1,46 ; 1,46$ x R\$ $28.425,85=\mathrm{R} \$ 41.691,25)$.

Quadro 2 - Caixa mínimo necessário

\begin{tabular}{|l|r|}
\hline Custo fixo mensal & $\mathrm{R} \$ 4.910,35$ \\
\hline Custo variável mensal & $\mathrm{R} \$ 23.515,50$ \\
\hline $\begin{array}{l}\text { Custo total da empresa } \\
\text { mensal }\end{array}$ & $\mathrm{R} \$ 28.425,85$ \\
\hline Custo total diário & $\mathrm{R} \$ 947,53$ \\
\hline $\begin{array}{l}\text { Necessidade Líquida de } \\
\text { Capital de Giro em dias }\end{array}$ & 44 \\
\hline Total & $\mathrm{R} \$ 41.691,25$ \\
\hline
\end{tabular}

Fonte: Os autores.

As despesas pré-operacionais representam todas as despesas que ocorrerão apenas no estágio inicial para a abertura e início dos trabalhos da agroindústria, conforme o Quadro 3. 
Quadro 3 - Despesas pré-operacionais

\begin{tabular}{|l|r|}
\hline \multicolumn{1}{|c|}{ Descrição } & \multicolumn{1}{c|}{ Valor } \\
\hline Despesas de Legalização & $\mathrm{R} \$ 350,00$ \\
\hline Obras civis e/ou reformas & $\mathrm{R} \$ 0,00$ \\
\hline Divulgação & $\mathrm{R} \$ 1.700,00$ \\
\hline Cursos e Treinamentos & $\mathrm{R} \$ 2.500,00$ \\
\hline Outras despesas & $\mathrm{R} \$ 1.200,00$ \\
\hline TOTAL & $\mathrm{R} \$ 5.750,00$ \\
\hline
\end{tabular}

Fonte: Os autores.

Já o Quadro 4 aponta a estimativa de capital de giro necessário de acordo com os itens necessários de produção.

Quadro 4 - Estimativa do capital de giro necessário

\begin{tabular}{|l|c|r|r|}
\hline Descrição & Qtde. & $\begin{array}{c}\text { Valor } \\
\text { Unitário }\end{array}$ & \multicolumn{1}{c|}{ Total } \\
\hline $\begin{array}{l}\text { Embalagens 500 } \\
\text { ml }\end{array}$ & 5000 & $\mathrm{R} \$ 0,32$ & $\begin{array}{r}\mathrm{R} \$ \\
1.600,00\end{array}$ \\
\hline $\begin{array}{l}\text { Essência de coco } \\
\text { e morango }\end{array}$ & 90 & $\mathrm{R} \$ 17,00$ & $\begin{array}{r}\mathrm{R} \$ \\
1.530,00\end{array}$ \\
\hline Açúcar & 90 & $\mathrm{R} \$ 1,39$ & $\mathrm{R} \$ 125,10$ \\
\hline Botijão de Gás & 2 & $\mathrm{R} \$ 45,00$ & $\mathrm{R} \$ 90,00$ \\
\hline $\begin{array}{l}\text { Leite in natura } \\
\text { Embalagens 1 } \\
\text { litro }\end{array}$ & 12000 & $\mathrm{R} \$ 0,95$ & $11.400,00$ \\
\hline $\begin{array}{l}\text { Filme polietileno } \\
\text { para } \\
\text { empacotamento - } \\
\text { Bobina 500 kg }\end{array}$ & 5000 & $\mathrm{R} \$ 0,38$ & $\begin{array}{r}\mathrm{R} \$ \\
1.900,00\end{array}$ \\
\hline $\begin{array}{l}\text { Fermento } \\
\text { industrial }\end{array}$ & 1 & $5.000,00$ & $\mathrm{R} \$$ \\
\hline Total & 90 & $\mathrm{R} \$ 70,00$ & $\mathrm{R} \$$ \\
\hline
\end{tabular}

Fonte: Os autores.

Somando-se todos os investimentos necessários para a implantação da agroindústria de beneficiamento de leite, tem-se $\mathrm{R} \$$ $246.982,35$. Esses valores se referem ao total do capital inicial necessário para a implantação efetiva da atividade e o capital de giro (Quadro 4) suficiente para custear o início da produção.

De posse dos investimentos iniciais necessários para a implantação da agroindústria, surgem também as estimativas de faturamento da empresa nascente em seu mês (Quadro 5).

Quadro 5 - Estimativa do faturamento mensal

\begin{tabular}{|l|c|c|c|}
\hline \multicolumn{1}{|c|}{ Produto } & $\begin{array}{c}\text { Quantida } \\
\text { de } \\
\text { (Estimati } \\
\text { va de } \\
\text { Vendas) }\end{array}$ & $\begin{array}{c}\text { Preço } \\
\text { Venda } \\
\text { Unitário }\end{array}$ & $\begin{array}{l}\text { Faturam } \\
\text { ento } \\
\text { Total }\end{array}$ \\
\hline $\begin{array}{l}\text { Iogurte } \\
500 \mathrm{ml}\end{array}$ & 8.400 & $\mathrm{R} \$ 1,60$ & $13.440,00$ \\
\hline $\begin{array}{l}\text { Leite } \\
\text { Pasteuriza } \\
\text { do }\end{array}$ & 3.600 & $\mathrm{R} \$ 1,30$ & \begin{tabular}{c}
$\mathrm{R} \$$ \\
\hline $\begin{array}{l}\text { Iogurte } \\
\text { litro }\end{array}$
\end{tabular} \\
\hline \multicolumn{2}{|l}{} & $\mathrm{R} \$ 2,70$ & $\begin{array}{c}\mathrm{R} \$ \\
11.340,00\end{array}$ \\
\hline Total & 4.200 & & $\mathrm{R} \$$ \\
\hline
\end{tabular}

Fonte: Os autores.

Com essa estimativa mensal de $\mathrm{R} \$ 29.460,00$, tem-se o montante do valor no primeiro ano de funcionamento da empresa totalizando R\$353.520,00.

Também foram calculados os custos unitários dos três produtos iniciais para a comercialização: iogurte em frasco de $500 \mathrm{ml}$ (Quadro 6), leite pasteurizado em embalagens de 1 litro (Quadro 7) e iogurte em frasco de 1 litro (Quadro 8). 
Quadro 6 - Estimativa de custo unitário para iogurte (embalagens de $500 \mathrm{ml}$ )

\begin{tabular}{|l|c|c|c|}
\hline $\begin{array}{c}\text { Materiais / Insumos } \\
\text { usados }\end{array}$ & Qtde & $\begin{array}{c}\text { Custo } \\
\text { Unitário }\end{array}$ & \multicolumn{1}{c|}{ Total } \\
\hline Embalagens 500 ml & 1 & $\mathrm{R} \$ 0,32$ & $\mathrm{R} \$ 0,32$ \\
\hline Essência & 0,01 & $\mathrm{R} \$ 17,00$ & $\mathrm{R} \$ 0,17$ \\
\hline Açúcar & 0,05 & $\mathrm{R} \$ 1,39$ & $\mathrm{R} \$ 0,07$ \\
\hline Leite in natura & 0,5 & $\mathrm{R} \$ 0,95$ & $\mathrm{R} \$ 0,48$ \\
\hline Fermento Industrial & 1 & $\mathrm{R} \$ 0,07$ & $\mathrm{R} \$ 0,07$ \\
\hline Total & & & $\mathbf{R} \$ \mathbf{1 , 1 0}$ \\
\hline
\end{tabular}

Fonte: Os autores.

Quadro 7 - Estimativa de custo unitário para leite pasteurizado (embalagens de 1 litro)

\begin{tabular}{|l|c|c|c|}
\hline $\begin{array}{c}\text { Materiais } \\
\text { / } \\
\text { Insumos } \\
\text { usados }\end{array}$ & Qtde & Custo Unitário & Total \\
\hline $\begin{array}{l}\text { Filme } \\
\text { plástico }\end{array}$ & 1 & $\mathrm{R} \$ 0,07$ & $\mathrm{R} \$ 0,07$ \\
\hline $\begin{array}{l}\text { Leite in } \\
\text { Natura }\end{array}$ & 1 & $\mathrm{R} \$ 0,95$ & $\mathrm{R} \$ 0,95$ \\
\hline Total & $\mathrm{R} \$ \mathbf{1 , 0 2}$ \\
\hline
\end{tabular}

Fonte: Os autores.

Quadro 8 - Estimativa de custo unitário para iogurte (embalagens de 1 litro)

\begin{tabular}{|l|c|c|c|}
\hline $\begin{array}{c}\text { Materiais } \\
\text { / Insumos } \\
\text { usados }\end{array}$ & Qtde & Custo Unitário & Total \\
\hline $\begin{array}{l}\text { Fermento } \\
\text { industrial }\end{array}$ & 2 & $\mathrm{R} \$ 0,14$ & $\mathrm{R} \$ 0,28$ \\
\hline Essência & 0,02 & $\mathrm{R} \$ 17,00$ & $\mathrm{R} \$ 0,34$ \\
\hline Açúcar & 0,1 & $\mathrm{R} \$ 1,39$ & $\mathrm{R} \$ 0,14$ \\
\hline $\begin{array}{l}\text { Leite in } \\
\text { natura }\end{array}$ & 1 & $\mathrm{R} \$ 0,95$ & $\mathrm{R} \$ 0,95$ \\
\hline Total & & $\mathbf{R} \$ \mathbf{1 , 7 1}$ \\
\hline
\end{tabular}

Fonte: Os autores.

Vale salientar que embora o sítio pertença a um produtor de leite, o espaço contará com a agroindústria que se responsabilizará pelo beneficiamento e comercialização do iogurte e do leite pasteurizado. Haverá a independência de ambas as atividades: a bovinocultura leiteira comercializará o leite para a agroindústria, motivo da existência do preço do leite in natura nos Quadros 6,7 e 8.

Além das informações sobre os custos unitários necessários para a produção foram calculadas também os custos de comercialização (Quadro 9).

Quadro 9 - Estimativa de custos de comercialização

\begin{tabular}{|l|r|r|r|}
\hline \multicolumn{1}{|c|}{ Descrição } & $(\boldsymbol{\%})$ & $\begin{array}{r}\text { Faturament } \\
\text { o Estimado }\end{array}$ & \multicolumn{1}{c|}{$\begin{array}{c}\text { Custo } \\
\text { Total }\end{array}$} \\
\hline $\begin{array}{l}\text { SIMPLES } \\
\text { (Imposto }\end{array}$ & & $\mathrm{R} \$$ & $\begin{array}{r}\mathrm{R} \$ \\
\text { Federal) }\end{array}$ \\
\hline $\begin{array}{l}\text { Comissões } \\
\text { (Gastos com } \\
\text { Vendas) }\end{array}$ & 4,0 & $29.460,00$ & $1.178,40$ \\
\hline $\begin{array}{l}\text { Propaganda } \\
\text { (Gastos com }\end{array}$ & & $\mathrm{R} \$$ & $\mathrm{R} \$$ \\
Vendas) & 4,0 & $29.460,00$ & $1.178,40$ \\
\hline $\begin{array}{l}\text { Taxas de } \\
\text { Cartões } \\
\text { (Gastos dom }\end{array}$ & & & $\mathrm{R} \$$ \\
Vendas) & 0,0 & $29.460,00$ & $\mathrm{R} \$ 0,00$ \\
\hline Total & & & $\mathrm{R}$ \\
(Impostos + & & & $\mathbf{R} \$$ \\
Gastos) & & & $\mathbf{3 . 3 8 7 , 9 0}$ \\
\hline
\end{tabular}

Fonte: Os autores.

Ao analisar as estimativas dos custos mensais, tem-se o total no primeiro de ano de $\mathrm{R} \$$ $40.654,80$. 
Foi considerada também a apuração mensal dos custos com as mercadorias que serão vendidas (Quadro 10) e calculada a apuração total no primeiro ano, chegando no valor de $\mathrm{R} \$$ 241.531,20.

Quadro 10 - Apuração mensal dos custos com mercadoria vendida

\begin{tabular}{|l|c|c|c|}
\hline Produto/Serviço & $\begin{array}{l}\text { Estimativa } \\
\text { de } \\
\text { Vendas (em } \\
\text { unidades) }\end{array}$ & $\begin{array}{c}\text { Custo } \\
\text { Unitário de } \\
\text { Materiais } \\
\text { /Aquisições }\end{array}$ & $\begin{array}{c}\text { CMD / } \\
\text { CMV }\end{array}$ \\
\hline Iogurte $500 \mathrm{ml}$ & 8.400 & $\mathrm{R} \$ 1,10$ & $\begin{array}{c}\mathrm{R} \$ \\
9.277,80\end{array}$ \\
\hline $\begin{array}{l}\text { Leite } \\
\text { Pasteurizado }\end{array}$ & 3.600 & $\mathrm{R} \$ 1,02$ & $\begin{array}{c}\mathrm{R} \$ \\
3.672,00 \\
\mathrm{R} \$\end{array}$ \\
\hline Iogurte litro & 4.200 & $\mathrm{R} \$ 1,71$ & $\begin{array}{c}\mathrm{7.177,80} \\
\mathbf{R} \$\end{array}$ \\
\hline Total & & & $\mathbf{2 0 . 1 2 7 , 6 0}$ \\
\hline
\end{tabular}

Fonte: Os autores.

Quadro 11 -Estimativa de custos com mão de obra

\begin{tabular}{|l|r|c|c|}
\hline \multicolumn{1}{|c|}{ Função } & \multicolumn{1}{|c|}{$\begin{array}{c}\text { Salário } \\
\text { Mensal }\end{array}$} & $\begin{array}{c}\text { Encargos } \\
\text { sociais }\end{array}$ & Total \\
\hline $\begin{array}{l}\text { Operação } \\
\text { Produção }\end{array}$ & $\begin{array}{r}\mathrm{R} \$ \\
1.000,00\end{array}$ & $\mathrm{R} \$ 160,00$ & $\mathrm{R} \$ 1.160,00$ \\
\hline $\begin{array}{l}\text { Serviços } \\
\text { Gerais }\end{array}$ & $\begin{array}{r}\mathrm{R} \$ \\
\mathrm{TOTAL}\end{array}$ & $\mathrm{R} 160,00$ & $\mathrm{R} \$ 1.160,00$ \\
\hline TOT & $\mathbf{R} \$ \mathbf{3 2 0 , 0 0}$ & $\mathbf{R} \$ \mathbf{2 . 3 2 0 , 0 0}$ \\
\hline
\end{tabular}

Fonte: Os autores.

Por ser uma agroindústria com mão de obra familiar, a empresa conseguirá gerar renda para dois filhos do produtor que passarão a trabalhar no negócio. O proprietário do negócio não trabalhará na agroindústria por necessitar conduzir as atividades agropecuárias do sítio, ficando a cargo da atividade de produção de leite (bovinocultura). Neste caso ele não terá prólabore do novo negócio, como aponta o Quadro 13.

Quadro 12 -Estimativas de custo com depreciação

\begin{tabular}{|l|c|c|c|}
\hline $\begin{array}{c}\text { Ativos } \\
\text { Fixos }\end{array}$ & $\begin{array}{c}\text { Valor do } \\
\text { bem }\end{array}$ & $\begin{array}{c}\text { Vida útil } \\
\text { (anos) }\end{array}$ & $\begin{array}{c}\text { Depreciaçã } \\
\text { o Anual }\end{array}$ \\
\hline Imóveis & $\begin{array}{c}\mathrm{R} \$ \\
100.800,00\end{array}$ & 25 & $\mathrm{R} \$ 4.032,00$ \\
\hline Máquinas & $\begin{array}{c}\mathrm{R} \$ \\
\mathrm{R} .750,00\end{array}$ & 10 & $\mathrm{R} \$ 4.275,00$ \\
\hline Móveis & $2.100,00$ & 10 & $\mathrm{R} \$ 210,00$ \\
\hline Veículos & $24.446,00$ & 5 & $\mathrm{R} \$ 4.889,20$ \\
\hline $\begin{array}{l}\text { Computad } \\
\text { ores }\end{array}$ & $\begin{array}{c}\mathrm{R} \$ \\
\mathrm{R} \$\end{array}$ & 3 & $\mathrm{R} \$ 500,00$ \\
\hline Total & $1.500,00$ & & $\begin{array}{c}\mathbf{R} \$ \\
\mathbf{1 3 . 9 0 6 , 2 0}\end{array}$ \\
\hline
\end{tabular}

Fonte: Os autores.

Ao calcular os custos fixos operacionais foi possível perceber que a agroindústria não terá valores monetários para o Imposto Predial Territorial Urbano (IPTU) e não pagará nenhum tipo de aluguel, visto que a agroindústria será implantada no sítio do produtor que almeja abrir este estabelecimento. Os demais valores constam nos Quadros 12 e 13. 
Quadro 13 - Estimativa de custos operacionais fixos

\begin{tabular}{|l|c|}
\hline \multicolumn{1}{|c|}{ Descrição } & Custo \\
\hline Energia elétrica & $\mathrm{R} \$ 500,00$ \\
\hline Telefone + internet & $\mathrm{R} \$ 100,00$ \\
\hline Honorários do contador & $\mathrm{R} \$ 250,00$ \\
\hline Pró-labore & $\mathrm{R} \$ 0,00$ \\
\hline $\begin{array}{l}\text { Manutenção dos } \\
\text { equipamentos }\end{array}$ & $\mathrm{R} \$ 2.320,00$ \\
\hline Salários + encargos & $\mathrm{R} \$ 350,00$ \\
\hline Material de limpeza & $\mathrm{R} \$ 20,00$ \\
\hline Material de escritório & $\mathrm{R} \$ 0,00$ \\
\hline Taxas diversas & $\mathrm{R} \$ 0,00$ \\
\hline Serviços de terceiros & $\mathrm{R} \$ 1.158,85$ \\
\hline Depreciação & $\mathrm{R} \$ 0,00$ \\
\hline $\begin{array}{l}\text { Contribuição } \\
\text { Empreendedor Individual }\end{array}$ & $\mathrm{R} \$ 61,50$ \\
\hline Outras taxas & $\mathbf{R} \$ \mathbf{4 . 9 1 0 , 3 5}$ \\
\hline TOTAL &
\end{tabular}

Fonte: Os autores.

Diante do valor mensal de $\mathrm{R} \$ 4.910,35$ referente aos custos operacionais fixos, tem-se o montante anual no valor de $\mathrm{R} \$ 58.924,20$.

\section{RESULTADOS E DISCUSSÃO}

O estudo foi estruturado de acordo com as normas e diretrizes do IMA que regulamenta a produção animal em nível estadual. Por isso, como anteriormente citado, o investimento inicial para a construção de uma indústria com capacidade para beneficiar 3.000 litros de leite por dia ficou estimado em $\mathrm{R} \$ 100.800,00$.

Contudo, como a estrutura desenvolvida seria demasiada grande, o ideal seria a construção das dependências físicas de acordo com as normas da Secretaria de Vigilância
Sanitária Municipal, fator que permitiria construir uma estrutura física que abrigasse apenas o suficiente para o beneficiamento e comercialização da produção de 200 a 400 litros/dia.

Ao verificar a legislação de alguns outros municípios vizinhos, foi possível identificar obras prediais com valor oscilando entre $\mathrm{R} \$ 10.000,00$ e $\mathrm{R} \$ 18.000,00$, a depender da legislação municipal em vigor, o que representaria uma economia aproximada de $82 \%$ sobre a construção utilizada nesse estudo, estimada em R $\$ 100.800,00$.

Pode-se considerar que, caso houvesse uma legislação municipal que regulamentasse a produção animal em Campestre, o beneficiamento do leite na propriedade seria um grande diferencial de mercado, por garantir qualidade e alta competitividade atrelada a melhores rentabilidades tanto na bovinocultura leiteira como na agroindústria.

Todavia, os resultados financeiros atingidos são adequados quando se avalia o contexto no qual estão inseridos. Primeiro, a atividade será capaz de empregar dois filhos do produtor que se preparam para ingressar no mercado de trabalho e poderão desenvolver suas atividades profissionais no negócio da família, contribuindo assim com a eventual redução do êxodo rural.

Por esse resultado, ocorre a satisfação do produtor que sonha com a possibilidade de 
proporcionar emprego e renda para os filhos que estão atingindo a idade adulta e se preparam para o mercado de trabalho.

Outra vantagem que possibilitaria ao produtor o desenvolvimento dessa atividade empresária é a possibilidade de comercialização da maior parte da produção para a Prefeitura Municipal de Campestre. A prefeitura necessita comprar da agricultura familiar municipal pelo menos $40 \%$ do total de alimentos consumidos nas escolas, e atualmente não compra pela inexistência de produtores que estejam com as produções agropecuárias legalmente aceitas.

Considerando que a Prefeitura Municipal possa comprar a produção,geraria um valor agregado pelo produto acima do preço de mercado (medida de incentivo à agricultura familiar), forçandoa renda da agroindústria a crescer. Porém, atualmente essa comparação não pôde ser feita pela inexistência da legislação municipal que regulamente a produção animal.

A bovinocultura leiteira é outro segmento da família que se beneficiaria com o beneficiamento na propriedade, pois conseguiria produzir um leite de maior qualidade, com mais valor agregado e conseguiria um preço diferenciado do mercado, garantindo assim maiores rentabilidades a ambas as atividades.

Já os resultados financeiros calculados no plano de negócios e apresentados permitem avaliar o resultado favorável da atividade, visto que a agroindústria conseguiu gerar lucro de $\mathrm{R} \$$ 1.034,15/mês além do salário mensal dos filhos de $\mathrm{R} \$ 1.000,00 /$ mês/filho. O demonstrativo dos resultados apresentados no Quadro 14 colaboram para a avaliação da situação econômica da atividade.

Quadro 14 - Demonstrativo dos resultados

\begin{tabular}{|l|c|c|}
\hline \multicolumn{1}{|c|}{ Descrição } & Valor & $\begin{array}{c}\text { Valor } \\
\text { Anual }\end{array}$ \\
\hline 1. Receita Total com Vendas & $\begin{array}{c}\mathrm{R} \$ \\
29.460,00\end{array}$ & $\begin{array}{c}\mathrm{R} \$ \\
353.520,00\end{array}$ \\
\hline 2. Custos Variáveis Totais & & \\
\hline $\begin{array}{c}\text { 2.1 (-) Custos com materiais } \\
\text { diretos e/ou CMV (*) }\end{array}$ & $\mathrm{R} \$$ & $\mathrm{R} \$$ \\
\hline 2.2 (-) Impostos sobre & $\mathrm{R} \$$ & $\mathrm{R} \$$ \\
vendas & $1.178,40$ & $14.140,80$ \\
\hline & $\mathrm{R} \$$ & $\mathrm{R} \$$ \\
2.3 (-) Gastos com vendas & $2.209,50$ & $26.514,00$ \\
\hline & $\mathrm{R} \$$ & $\mathrm{R} \$$ \\
Total de custos variáveis & $23.515,50$ & $282.186,00$ \\
\hline & $\mathrm{R} \$$ & $\mathrm{R} \$$ \\
3. Margem de Contribuição & $5.944,50$ & $71.334,00$ \\
\hline & $\mathrm{R} \$$ & $\mathrm{R} \$$ \\
4. (-) Custos Fixos Totais & $4.910,35$ & $\mathbf{5 8 . 9 2 4 , 2 0}$ \\
\hline 5. Resultado Operacional: & $\mathbf{R} \$$ & $\mathbf{R} \$$ \\
LUCRO & $\mathbf{1 . 0 3 4 , 1 5}$ & $\mathbf{1 2 . 4 0 9 , 8 0}$ \\
\hline
\end{tabular}

Fonte: Os autores.

A lucratividade conseguida, após todas as tributações e após o pagamento de todas as depreciações, representa o valor aproximado de $3,51 \%$ sobre o faturamento total da empresa.

Quadro 15 - Indicadores de Viabilidade

\begin{tabular}{|l|c|}
\hline \multicolumn{1}{|c|}{ Indicadores } & Ano 1 \\
\hline $\begin{array}{l}\text { Ponto de } \\
\text { Equilíbrio }\end{array}$ & $\mathrm{R} \$ 292.019,00$ \\
\hline Lucratividade & $3,51 \%$ \\
\hline Rentabilidade & $5,02 \%$ \\
\hline $\begin{array}{l}\text { Prazo de retorno } \\
\text { de investimento }\end{array}$ & 19 anos e 11 meses \\
\hline
\end{tabular}

Fonte: Os autores. 
A rentabilidade do negócio, outro indicador fundamental para a avaliação da viabilidade econômica foi baixa, considerando fundos de investimentos seguros que rendem entre 6 e 7\% ao ano, a rentabilidade da agroindústria foi de 5,02\%.

Diante dos altos custos do investimento inicial, que acabaram por influenciar os custos mensais da empresa, o ponto de equilíbrio situado em R $\$ 292.019,00 /$ ano ou R \$24.334,92/mês são altos, visto que a empresa faturaria aproximadamente $\mathrm{R} \$ 29.000,00 /$ mês. Tal situação colocaria a agroindústria em uma situação de vulnerabilidade econômica, caso o mercado sofresse qualquer alteração ou recessão futura.

O prazo de retorno do investimento, ou bayback, ficou em quase 20 anos, algo que compromete a motivação do produtor pelo tempo tão longo para se conseguir recuperar todo o capital investido na atividade.

\section{REFERÊNCIAS BIBLIOGRÁFICAS}

\section{AUSTIN J.; STEVENSON H.; WEL-}

SKILLERN J. Social and commercial entrepreneurship: same, different, or both?.

Revista de Administração USP. São Paulo, v. 47, n. 3, p. 370-384. jul/ago/set. 2012.

\section{CHIAVENATO, I. Planejamento e Controle da}

Produção. $2^{\mathrm{a}} \mathrm{d}$. Tamboré: Manole, 2008.

HUMPHREY, J. Policy implications of trends in agribusiness value chains. The European

Journal of Development Research, v.18, n.4, p.572-592, 2006. 